\title{
Adrenocorticotropic hormone (ACTH)-producing pheochromocytoma presented as Cushing syndrome and complicated by invasive aspergillosis
}

\author{
Jae Ho Cho', Da Eun Jeong1, Jae Young Lee', Jong Geol Jang', Jun Sung Moon', Mi Jin Kim², \\ Ji Sung Yoon', Kyu Chang Won', Hyoung Woo Lee ${ }^{1}$ \\ Departments of ${ }^{1}$ Internal Medicine and ${ }^{2}$ Pathology, College of Medicine, Yeungnam University, Daegu, Korea
}

\begin{abstract}
Adrenocorticotropic hormone (ACTH)-producing pheochromocytoma has been rarely reported, whereas only a few cases of Cushing syndrome accompanied by opportunistic infections have been reported. We experienced a patient with pheochromocytoma with ectopic Cushing syndrome complicated by invasive aspergillosis. A 35-year-old woman presented with typical Cushingoid features. Her basal plasma cortisol, ACTH, and 24-hour urine free cortisol levels were significantly high, and 24-hour urine metanephrine and catecholamine levels were slightly elevated. The endogeneous cortisol secretion was not suppressed by either low- or high-dose dexamethasone. Abdominal computed tomography (CT) revealed a heterogeneous enhancing mass measuring approximately $2.5 \mathrm{~cm}$ in size in the left adrenal gland. No definitive mass lesion was observed on sellar magnetic resonance imaging. On fluorine-18 fluorodeoxyglucose positron emission tomography/CT, a hypermetabolic nodule was observed in the left upper lung. Thus, we performed a percutaneous needle biopsy, which revealed inflammation, not malignancy. Thereafter, we performed a laparoscopic left adrenalectomy, and its pathologic finding was a pheochromocytoma with positive immunohistostaining for ACTH. After surgery, the biochemistry was normalized, but the clinical course was fatal despite intensive care because of the invasive aspergillosis that included the lungs, retina, and central nervous system.
\end{abstract}

Keywords: ACTH syndrome; Ectopic; Cushing syndrome; Pheochromocytoma; Aspergillosis

\section{INTRODUCTION}

Ectopic adrenocorticotropic hormone (ACTH)-dependent Cushing syndrome comprises approximately $10 \%$ of Cushing syndrome [1]. The most common causes of ectopic ACTH syndrome are malignancies that include small cell lung cancer (SCLC), bronchial carcinoids, islet cell tumors of the pancreas, thymic carcinoids, and medullary thyroid cancer. ACTH-producing pheochromocytoma is one cause of ectopic ACTH syndrome, which has been reported to range from $2 \%$ to $25 \%$ [2-8], fewer than 30 cases globally and only 3 cases have been reported in Korea [9-12].

Received: July 24, 2014, Revised: September 12, 2014, Accepted: September 15, 2014

Corresponding Author: Hyoung Woo Lee, Department of Internal Medicine, College of Medicine, Yeungnam University, 170 Hyeonchung-ro, Namgu, Daegu 42415, Korea Tel: +82-53-620-3839, Fax: +82-53-623-8006

E-mail: Ihw5809@ynu.ac.kr
Endogenous and iatrogenic hypercortisolism is known to impair cell-mediated immunity, making patients with Cushing syndrome susceptible to opportunistic infections such as mucocutaneous and invasive fungal infections, viral infections, bacterial infections, reactivation of tuberculosis, and post-operative wound infections $[13,14]$. However, invasive aspergillosis is rarely reported in patients with Cushing syndrome. This case is the first report of invasive aspergillosis complicated by ACTH-producing pheochromocytoma.

\section{CASE}

A 35-year-old woman was admitted to our hospital due to headache for 2 months. She also suffered from proximal muscle weakness and ocular pain. She had not had any other disease, but 2 months before her admission, she was diagnosed with hypertension and treated with 3 kinds of antihypertensive drugs (an $\alpha 1$-receptor blocker, a calcium antag- 
onist, and an angiotensin-2 receptor blocker). On physical examination, she presented typical Cushingoid features, including centripetal obesity with slim extremities, a buffalo hump, a moon face, and hirsutism. She had gained over 6 $\mathrm{kg}$ in weight from 2 months earlier. Her weight was $56 \mathrm{~kg}$; height, $155 \mathrm{~cm}$ (body mass index, $23.31 \mathrm{~kg} / \mathrm{m}^{2}$ ); body temperature, $37.2^{\circ} \mathrm{C}$; pulse, 70 beats $/ \mathrm{min}$; and blood pressure, $140 / 90 \mathrm{mmHg}$.

The laboratory findings at presentation were severe hypercortisolism with loss of diurnal variation, hypokalemia, and glucose intolerance. The basal plasma cortisol levels were over $49 \mu \mathrm{g} / \mathrm{dL}$ at both 8:00 a.m. and 4:00 p.m. (normal range [NR], 5-25 $\mu \mathrm{g} / \mathrm{dL}$ at 8:00 a.m. and 3-13 $\mu \mathrm{g} / \mathrm{dL}$ at 4:00 p.m.), and the plasma ACTH levels were $357.89 \mathrm{pg} / \mathrm{mL}$ (NR, 10-60 $\mathrm{pg} / \mathrm{mL})$ and $289.54 \mathrm{pg} / \mathrm{mL}(\mathrm{NR}, 6-30 \mathrm{pg} / \mathrm{mL})$ at 8:00 a.m. and 4:00 p.m., respectively. However, the plasma epinephrine (48.24 pg/mL; NR, <120 pg/mL) and norepinephrine (210.04 $\mathrm{pg} / \mathrm{mL} ; \mathrm{NR}, 0-410 \mathrm{pg} / \mathrm{mL}$ ) levels were not elevated. The 24-hour urine free cortisol level (5,600 $\mu \mathrm{g} /$ day; NR, 20-90 $\mu \mathrm{g} /$ day) was significantly elevated; the 24 -hour urine epine-

Table 1. Endocrinologic studies before and after surgery (16 weeks)

\begin{tabular}{|c|c|c|c|}
\hline Hormonal profiles & $\begin{array}{c}\text { Reference } \\
\text { range }\end{array}$ & $\begin{array}{l}\text { Before } \\
\text { surgery }\end{array}$ & $\begin{array}{c}\text { After } \\
\text { surgery }\end{array}$ \\
\hline \multicolumn{4}{|l|}{ Serum cortisol $(\mu \mathrm{g} / \mathrm{dL})$} \\
\hline Basal (8:00 a.m.) & $5-25$ & $>49$ & 24 \\
\hline Basal (4:00 p.m.) & $3-13$ & $>49$ & \\
\hline After low-dose suppression & & $>49$ & \\
\hline After high-dose suppression & & $>49$ & \\
\hline \multicolumn{4}{|l|}{ Serum ACTH (pg/mL) } \\
\hline Basal (8:00 a.m.) & $10-60$ & 357.89 & 47 \\
\hline Basal (4:00 p.m.) & $6-30$ & 289.54 & \\
\hline Serum epinephrine $(\mathrm{pg} / \mathrm{mL})$ & $<120$ & 48.24 & \\
\hline Serum norepinephrine $(\mathrm{pg} / \mathrm{mL})$ & $0-410$ & 210.04 & \\
\hline Serum DHEA-S ( $\mu \mathrm{g} / \mathrm{dL})$ & $30-333$ & 379.82 & \\
\hline \multicolumn{4}{|l|}{ 24-hr urine free cortisol $(\mu \mathrm{g} /$ day $)$} \\
\hline Basal & $20-90$ & 5,600 & 298 \\
\hline After low-dose suppression & & $>5,000$ & \\
\hline After high-dose suppression & & 5,565 & \\
\hline 24-hr urine epinephrine ( $\mu \mathrm{g} /$ day) & $0-20$ & 44.3 & \\
\hline 24-hr urine norepinephrine ( $\mu \mathrm{g} /$ day) & $15-80$ & 121.6 & \\
\hline 24-hr urine VMA (mg/day) & $0-8$ & 2.6 & \\
\hline 24-hr urine metanephrine (mg/day) & $<0.8$ & 1.8 & \\
\hline
\end{tabular}

ACTH, adrenocorticotropic hormone; DHEA-S, dehydroepiandrosterone-sulfate; VMA, vanillylmandelic acid. phrine (44.3 $\mu \mathrm{g} /$ day; NR, 0-20 $\mu \mathrm{g} /$ day), norepinephrine (121.6 $\mu \mathrm{g} /$ day; $\mathrm{NR}, 15-80 \mu \mathrm{g} /$ day $)$, and metanephrine $(1.8 \mathrm{mg} /$ day; $\mathrm{NR},<0.8 \mathrm{mg} /$ day) levels and the plasma dehydroepiandrosterone-sulfate level (379.82 $\mu \mathrm{g} / \mathrm{dL}$; NR, 30-333) were slightly elevated; and the 24-hour urine vanillymandelic acid (VMA) level (2.6 mg/day; NR, 0-8 mg/day) was not elevated. The serum potassium level was $2.4 \mathrm{mEq} / \mathrm{L}(\mathrm{NR}, 3.5-5.5 \mathrm{mEq} / \mathrm{L})$; the plasma glucose level, $197 \mathrm{mg} / \mathrm{dL}(\mathrm{NR}, 72-110 \mathrm{mg} / \mathrm{dL})$; and the glycohemoglobin (HbA1c) level, 6.4\% (NR, 4.4\%-6.3\%). Endogenous cortisol secretion was not suppressed by either the standard low-dose $(0.5 \mathrm{mg}$ every 6 hours for 2 days) or high-dose dexamethasone ( $2 \mathrm{mg}$ every 6 hours for 2 days) suppression tests, which led to the diagnosis of ectopic ACTH syndrome. The results of the endocrinologic study are summarized in Table 1.

On abdominal computed tomography (CT), a heterogeneous enhancing round mass measuring approximately $2.5 \mathrm{~cm}$ in size was observed in the left adrenal gland (Fig. 1). To exclude ACTH overproduction by the pituitary gland, sellar magnetic resonance imaging (MRI) was performed, which found no evidence of pituitary adenoma (Fig. 2). To search for a source of ectopic ACTH production, fluorine-18 fluorodeoxyglucose positron emission tomography (F-18 FDG PET)/CT was performed, on which a focal hypermetabolic nodule was observed in the left upper lung. Enlargement of both adrenal glands and a mass in the left adrenal gland with FDG uptake were also observed on PET/CT (Fig. 3). A cavitary nodule measuring approximately $1.2 \mathrm{~cm}$ in size with a sur-

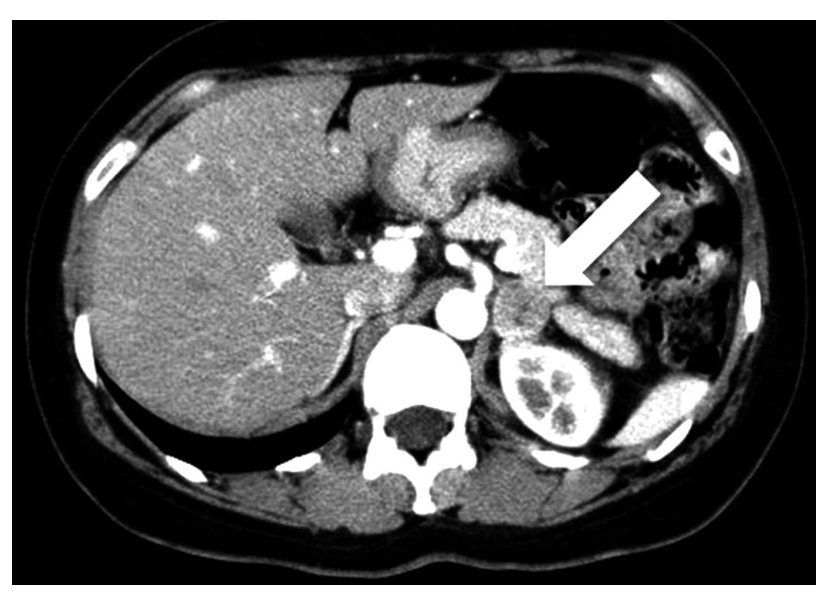

Fig. 1. Abdominal computed tomography scan showing a heterogeneous enhancing round mass (arrow) measuring approximately $2.5 \mathrm{~cm}$ in the left adrenal gland (32 Hounsfield units in the left adrenal gland in the non-contrast phase). 


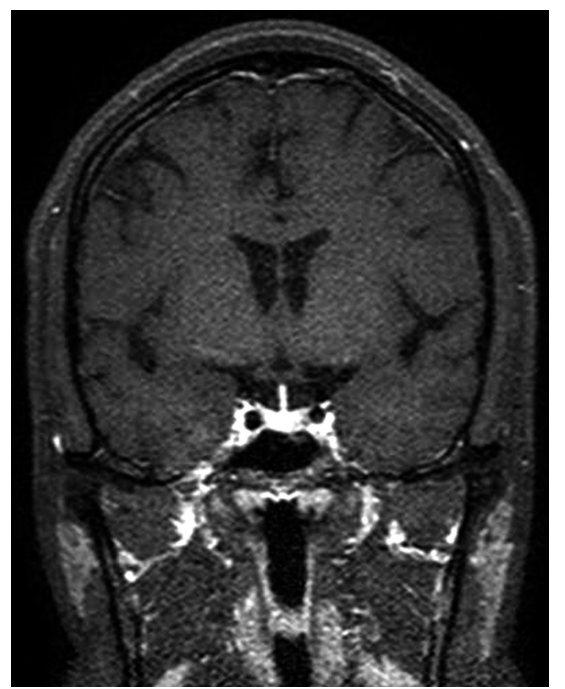

Fig. 2. Sellar magnetic resonance imaging scan showing no definite evidence of abnormal lesions in the pituitary gland.

rounding ground glass appearance in the left upper lung was observed on chest CT (Fig. 4). At first, we considered ectopic ACTH-producing lung cancer; therefore, we performed a percutaneous needle biopsy of the lung nodule. However, the pathologic result was inflammation, not malignancy. Based on these findings, we diagnosed ectopic ACTH syndrome of the adrenal adenoma and performed laparoscopic left adrenalectomy.

In examination of the resected specimen, the left adrenal gland measured $6.0 \times 4.3 \times 2.3 \mathrm{~cm}$ and weighed $22 \mathrm{~g}$. We found a solid round tumor with a diameter of approximately $2.4 \mathrm{~cm}$. The cut surface of the tumor showed a dark brown to gray color and focal hemorrhage (Fig. 5A). The histological finding was pheochromocytoma with oval to polygonal cells and abundant acidophilic cytoplasmic granules, a round nucleus, a clear vacuolated cytoplasm, and increased vascularity. Mitosis or capsular invasion was not seen. The left adrenal gland showed mild cortical hyperplasia (Fig. 5B). Immunohistochemistry showed that the tumor cells were strongly positive-stained for ACTH (Fig. 5C) and negative-stained for inhibin.

After surgery, the biochemistry normalized (Table 1), but the clinical course was fatal due to the complication of invasive aspergillosis in the lung, retina, and central nervous system. The day after surgery, fever developed; and 2 days later, the patient complained of dyspnea. The chest X-ray showed multifocal dense consolidation and partial cavity for-
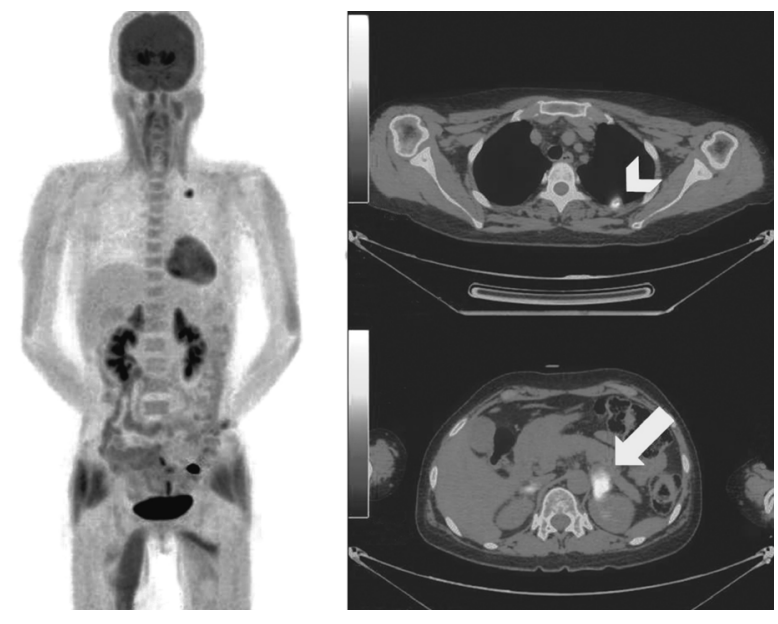

Fig. 3. Fluorine-18 fluorodeoxyglucose positron emission tomography/computed tomography scan showing a focal hypermetabolic nodule in the left upper lung (arrowhead) and a mass in the left adrenal gland (arrow).

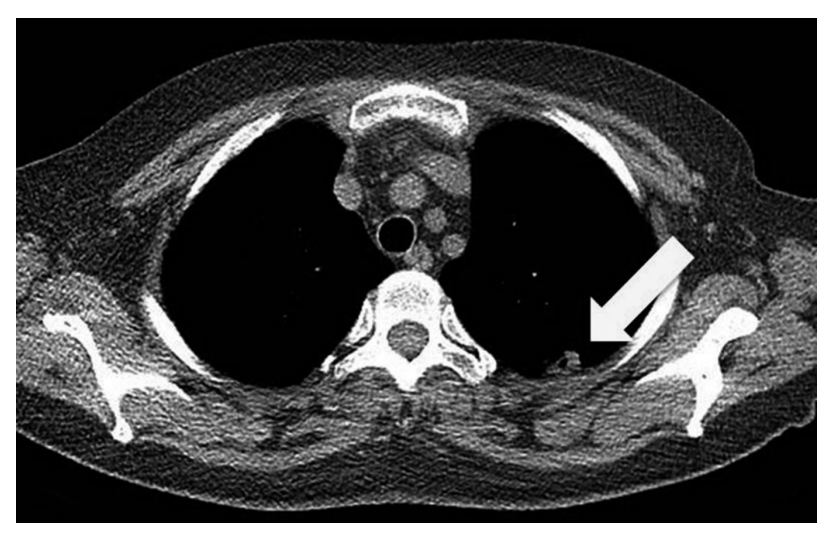

Fig. 4. Chest computed tomography scan showing a cavitary nodule (arrow) measuring approximately $1.2 \mathrm{~cm}$ with a surrounding ground glass appearance in the left upper lung.

mation in both lungs. On the 5th post-operative day, the chest CT showed more aggravated multifocal patchy consolidation, a ground glass appearance, and new formation of cavities in both lungs (Fig. 6A). The sputum cultures revealed the Aspergillus species, and the result of aspergillus antigen test was positive. The patient was treated with intravenous voriconazole. On the 6th post-operative day, the patient complained of visual disturbance of the right eye. Fundus photography revealed inflammatory ball-like lesions in the vitreous cavity and neovascular fibroproliferation that demonstrated fungal retinitis (Fig. 6B). On the 10th post-operative day, the patient became stuporous. Brain CT showed multifocal lowdensity areas in both cerebral hemispheres and the right 

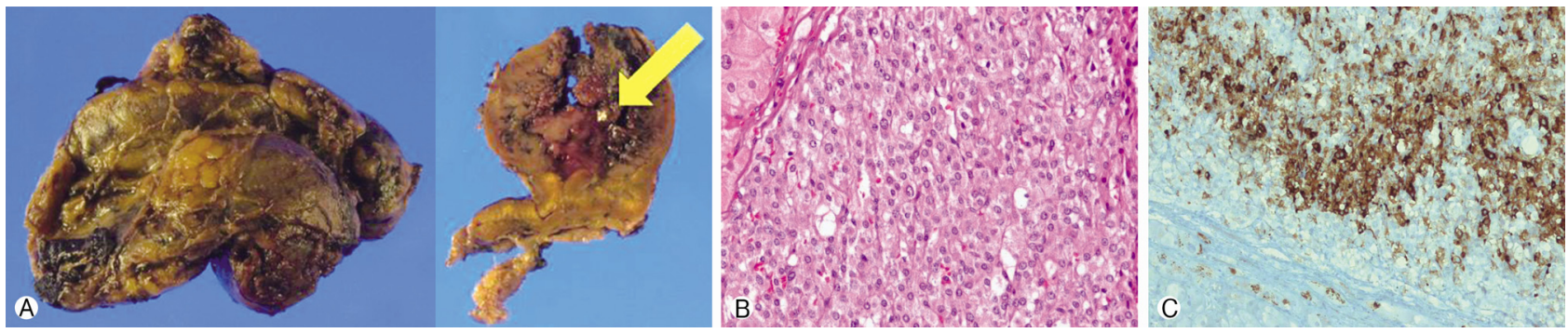

Fig. 5. (A) Gross finding. The left adrenal gland shows a dark brown colored mass measuring approximately $2.4 \mathrm{~cm}$ in size (arrow). (B) Histological findings. The tumor is composed of oval to polygonal cells with round nuclei and abundant acidophilic or clear vacuolated cytoplasm (H\&E stain, $\times 200)$. (C) The tumor cells are positive for adrenocorticotropic hormone (immunohistochemical stain, $\times 100$ ).
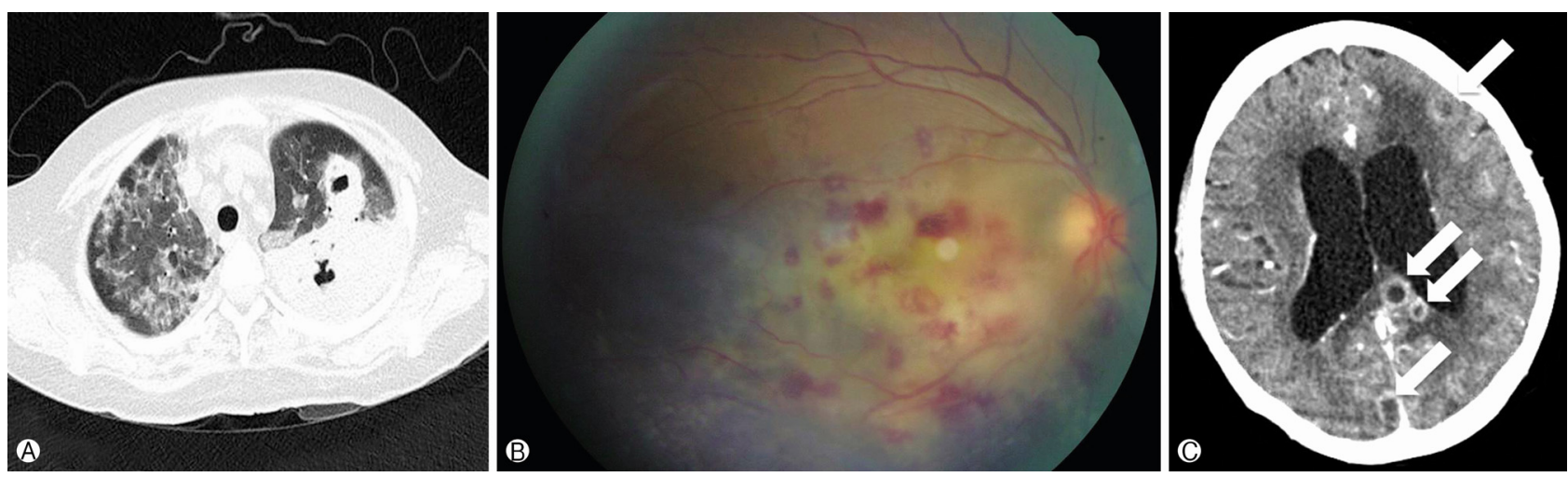

Fig. 6. (A) Chest computed tomography (CT) scan showing pulmonary aspergillosis, including multifocal patchy consolidation, a ground glass appearance, and formation of cavities in both lungs. (B) Fundus photograph showing inflammatory ball-like lesions and neovascular fibroproliferation in the right eye indicative of fungal retinitis. (C) Brain CT scan showing multiple ring enhancing masses (arrows) from the cerebral aspergillosis.

cerebellum. Despite continuous antifungal treatment, the patient's mental status showed further deterioration. Brain CT was performed repeatedly, which showed multiple ring enhancing masses from the cerebral aspergillosis (Fig. 6C). Despite administration of antifungal and broad-spectrum antibiotics therapy, the patient died on the 233th day of her hospitalization.

\section{DISCUSSION}

Cushing syndrome is a rare disorder with an annual incidence of 0.7-2.4 per million population. Overall, ACTH-dependent causes account for approximately $80 \%-85 \%$ of all cases, and of these, $80 \%$ are due to pituitary adenomas $(\mathrm{Cu}-$ shing disease), and the remaining 20\% are due to ectopic ACTH syndrome. Approximately $10 \%-15 \%$ of cases are caused by an ACTH-independent adrenal source [1]. The most common causes of ectopic ACTH syndrome are malignancies that include SCLC, bronchial carcinoids, islet cell tumors of the pancreas, thymic carcinoids, and medullary thyroid cancer. Of these, bronchial carcinoids seem to be by far the most common tumors. Because the SCLC patients' condition, they did not have time to go to a reference center [8]. Pheochromocytoma accounts for $2 \%-25 \%$ of overt cases of ectopic ACTHsecreting tumors [2-8]. Fewer than 30 cases have been reported globally. Nijhoff et al. [9] reviewed 24 cases of Cushing syndrome caused by pheochromocytoma reported between 1977 and 2009. Only 3 cases have been reported in Korea. Hong et al. [10] were the first to report on a patient with ACTH-producing pheochromocytoma in 1997. However, to the best of our knowledge, this is the first report of a patient with ACTH-producing pheochromocytoma complicated by invasive aspergillosis.

Due to the highly variable phenotype, clinical diagnosis of ACTH-producing pheochromocytoma is very difficult. Some cases have no typical Cushingoid symptoms, and some have 
no typical features of catecholamine excess. Chen et al. [15] proposed the following diagnostic criteria for Cushing syndrome caused by pheochromocytoma: (1) clinical and laboratory evidence of hypercortisolism; (2) elevated plasma ACTH levels; (3) evidence of pheochromocytoma in the urinary catecholamine, metanephrine, or VMA levels, or MRI evidence of an adrenal mass with a bright T2 signal; (4) resolution of symptoms/signs of adrenocorticoid and catecholamine excess after unilateral adrenalectomy; and (5) rapid normalization of the plasma ACTH levels after adrenalectomy. In our patient, the normal plasma catecholamine and 24-hour urine VMA levels, and the slightly elevated 24-hour urine catecholamine and metanephrine levels, led us initially to reject the possibility of pheochromocytoma as the ectopic source of the ACTH secretion. The cause of the low levels of urinary metanephrine and VMA was speculated as the negative effect of the hypercortisolism or ectopic ACTH production on the detection of urinary metanephrine excretion or the metabolic process of catecholamine that includes monoamine oxidase or catechol-O-methyltransferse activation [16]. Therefore, a high index of suspicion is required for early diagnosis of adrenal pheochromocytoma as the source of ectopic Cushing syndrome, together with a laboratory study, imaging findings, invasive procedures (such as sampling of ACTH in the adrenal veins), and clinical characteristics.

Excessive corticosteroid impairs cell-mediated immunity. Thus, patients with Cushing syndrome are susceptible to opportunistic infections [14]. Patients with endogenous Cushing syndrome have the same spectrum of infections as patients with iatrogenic Cushing syndrome. The risk of infection is correlated with the degree of cortisol excess [13]. Therefore, the fatality rate for endogenous Cushing syndrome is higher than that for iatrogenic Cushing syndrome [14]. Furthermore, the type of infection depends on the degree of cortisol excess. For example, Graham and Tucker [13] reported that cryptococcosis occurred with a less than $1,933 \mathrm{nmol} / \mathrm{L}$ morning plasma cortisol level. However, the Pneumocystis jirovecii pneumonia (PJP) threshold was much higher, as morning cortisol levels above $3,342 \mathrm{nmol} / \mathrm{L}$ are associated with pneumocystosis. In immunocompetent hosts, there are normally 2 lines of defense against inhaled molds. First, the resident lung macrophages facilitate phagocytosis, and, second, polymorphonuclear leukocytes destroy the hyphae. Glucocorticoids negatively affect this mechanism, and thus, produce an immuno- suppressive condition.

Several invasive fungal infections, including cryptococcosis, PJP, invasive aspergillosis, invasive candidiasis, and histoplasmosis, have been reported in endogenous Cushing syndrome [17]. Invasive aspergillosis is the most common invasive mold infection associated with glucocorticoids [14]. Cases of invasive aspergillosis in ectopic ACTH syndrome have been reported. Among them, Naylor et al. [18] reported pulmonary aspergillosis and endophthalmitis in ectopic ACTH syndrome caused by bronchial carcinoids, and Walsh and Mendelsohn [19] reported pulmonary and disseminated aspergillosis in ectopic ACTH syndrome caused by prostate carcinoma.

The prognosis of ACTH-producing pheochromocytoma is worse than that of bronchial carcinoids. The observed mortality rate was $20 \%[2,3,5]$. Rapid control of hypercortisolemia is crucial for survival. In our patient, the biopsy-confirmed inflammatory left lung nodule was considered a source of invasive aspergillosis, which was disseminated after surgery.

In summary, we presented a patient with ectopic ACTHproducing pheochromocytoma complicated by invasive aspergillosis. These invasive fungal infections have fatal outcomes because of their immunosuppressive condition due to hypercortisolism. Thus, careful attention and prompt management are needed in treatment of these patients.

\section{REFERENCES}

1. Newell-Price J, Bertagna X, Grossman AB, Nieman LK. Cushing's syndrome. Lancet 2006;367(9522):1605-17.

2. Isidori AM, Kaltsas GA, Pozza C, Frajese V, Newell-Price J, Reznek RH, et al. The ectopic adrenocorticotropin syndrome: clinical features, diagnosis, management, and long-term follow-up. J Clin Endocrinol Metab 2006;91:371-7.

3. Ilias I, Torpy DJ, Pacak K, Mullen N, Wesley RA, Nieman LK. Cushing's syndrome due to ectopic corticotropin secretion: twenty years' experience at the National Institutes of Health. J Clin Endocrinol Metab 2005;90:4955-62.

4. Salgado LR, Fragoso MC, Knoepfelmacher M, Machado MC, Domenice S, Pereira MA, et al. Ectopic ACTH syndrome: our experience with 25 cases. Eur J Endocrinol 2006;155: 725-33.

5. Bhansali A, Walia R, Rana SS, Dutta P, Radotra BD, Khandelwal N, et al. Ectopic Cushing's syndrome: experience from a tertiary care centre. Indian J Med Res 2009;129: 33-41.

6. Isidori AM, Lenzi A. Ectopic ACTH syndrome. Arq Bras Endocrinol Metabol 2007;51:1217-25. 
7. Wajchenberg BL, Mendonca BB, Liberman B, Pereira MA, Carneiro PC, Wakamatsu A, et al. Ectopic adrenocorticotropic hormone syndrome. Endocr Rev 1994;15:752-87.

8. Alexandraki KI, Grossman AB. The ectopic ACTH syndrome. Rev Endocr Metab Disord 2010;11:117-26.

9. Nijhoff MF, Dekkers OM, Vleming LJ, Smit JW, Romijn JA, Pereira AM. ACTH-producing pheochromocytoma: clinical considerations and concise review of the literature. Eur J Intern Med 2009;20:682-5.

10. Hong YS, Kim HJ, Sung YA, Kyung NH, Kim HJ, Kim SS. A case of pheochromocytoma associated with ectopic ACTH syndrome. J Korean Soc Endocrinol 1997;12:99-104. Korean.

11. Oh HC, Koh JM, Kim MS, Park JY, Shong YK, Lee KU, et al. A case of ACTH-producing pheochromocytoma associated with pregnancy. Endocr J 2003;50:739-44.

12. Moon JM, Kim YJ, Seo YJ, Choi HY, Kim JH, Park JR, et al. Ectopic ACTH syndrome with bilateral pheochromocytoma in multiple endocrine neoplasia type 2A. J Korean Endocr Soc 2009;24:265-71.

13. Graham BS, Tucker WS Jr. Opportunistic infections in endo- genous Cushing's syndrome. Ann Intern Med 1984;101:334-8.

14. Lionakis MS, Kontoyiannis DP. Glucocorticoids and invasive fungal infections. Lancet 2003;362(9398):1828-38.

15. Chen H, Doppman JL, Chrousos GP, Norton JA, Nieman LK, Udelsman R. Adrenocorticotropic hormone-secreting pheochromocytomas: the exception to the rule. Surgery 1995; 118:988-94

16. Otsuka F, Miyoshi T, Murakami K, Inagaki K, Takeda M, Ujike K, et al. An extra-adrenal abdominal pheochromocytoma causing ectopic ACTH syndrome. Am J Hypertens 2005; 18:1364-8.

17. Findling JW, Tyrrell JB, Aron DC, Fitzgerald PA, Young CW, Sohnle PG. Fungal infections in Cushing's syndrome. Ann Intern Med 1981;95:392.

18. Naylor CD, Shkrum MJ, Edmonds MW, Cholod EJ. Pulmonary aspergillosis and endophthalmitis: complications of Cushing's syndrome. CMAJ 1988;138:719-20.

19. Walsh TJ, Mendelsohn G. Invasive aspergillosis complicating Cushing's syndrome. Arch Intern Med 1981;141:1227-8. 